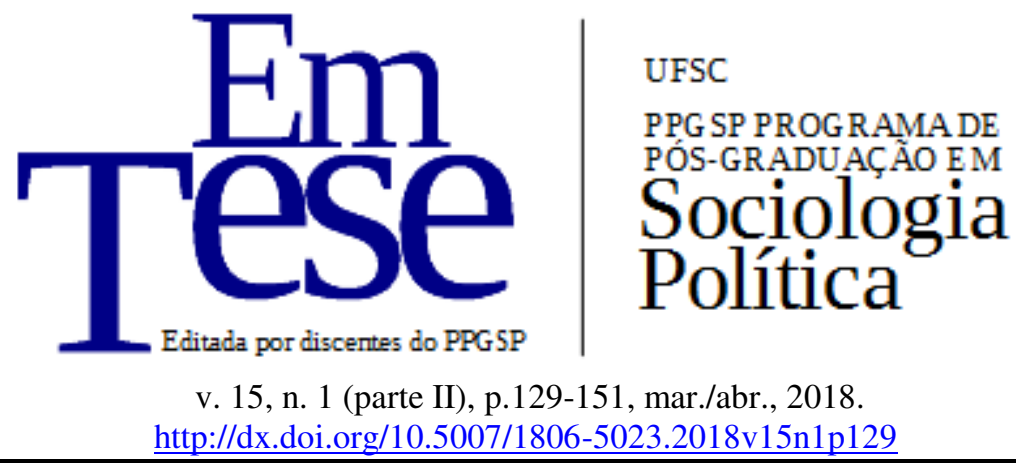

\title{
Para além do neoliberalismo e da social-democracia: uma análise do liberalismo social de José Guilherme Merquior ${ }^{1}$
}

Kaio Felipe ${ }^{2}$

Resumo: O propósito deste trabalho é analisar a doutrina do liberalismo social tal como defendida pelo diplomata e sociólogo José Guilherme Merquior (1941-1991). Pretendo compreender o peso de cada uma das principais influências que Merquior mescla no seu ideário político: o "liberalismo de esquerda" de Hobhouse, Green e Keynes; o liberalismo humanista de Humboldt; a ênfase na individualidade de Stuart Mill; a síntese democráticoliberal de Aron e Bobbio; e o liberalismo econômico de Hayek. Por fim, cabe investigar, a partir das críticas de Merquior à social-democracia (acusada de ineficiência econômica) e ao neoliberalismo (criticado por seu déficit democrático), como ele se situava no debate político no Brasil dos anos 1980, época marcada pela redemocratização e por uma aguda crise econômica.

Palavras-chave: pensamento político brasileiro; liberalismo; social-democracia.

\section{Beyond neoliberalism and social democracy: an analysis of José Guilherme Merquior's social liberalism}

Abstract: This paper aims to analyze the doctrine of social liberalism as defended by the diplomat and sociologist José Guilherme Merquior (1941-1991). The purpose is to understand the weight of each of the main influences that Merquior combines in his political ideology: Hobhouse, Green and Keynes "left-liberalism"; Humboldt's humanistic liberalism; Stuart Mill's emphasis on individuality; Aron and Bobbio's democratic-liberal synthesis; and Hayek's economic liberalism. Finally, it is worth investigating Merquior's critiques of social democracy (accused of economic inefficiency) and neoliberalism (criticized by its democratic deficit), and how he stood in the political debate in Brazil in the 1980s, a period marked by the democratization and an acute economic crisis.

Keywords: Brazilian political thought; liberalism; social democracy.

\footnotetext{
1 (cc) EY Esta obra está licenciada com uma Licença Creative Commons Atribuição 4.0 Internacional.

${ }^{2}$ Doutorando em Sociologia e mestre em Ciência Política pelo Instituto de Estudos Sociais da Universidade do Estado do Rio de Janeiro (IESP-UERJ).E-mail: kaiofelipe@gmail.com
} 


\section{Introdução}

No Brasil, a despeito da "condição periférica" que nossos próprios intelectuais tomam como pressuposto de nosso pensamento político (cf. LYNCH, 2013) ${ }^{3}$, seria possível a um pensador "elaborar reflexões filosóficas pessoais, voltadas para os problemas específicos da cultura brasileira" (MARGUTTI, 2013 apud RAZZO, 2014, p. 172) e ao mesmo tempo se inserir no debate internacional, em pé de igualdade com intelectuais do Atlântico Norte? Pelo menos quanto a José Guilherme Merquior (1941-1991), a resposta é afirmativa.

Diplomata, membro da Academia Brasileira de Letras e doutor em Letras pela Universidade de Paris e em Sociologia pela London School of Economics and Political Science, Merquior desenvolveu uma trajetória impressionante: em menos de três décadas escreveu obras relevantes em áreas tão diversas como crítica literária, antropologia e teoria política; algumas delas, como Foucault, ou O Niilismo de Cátedra (1985) e O Marxismo Ocidental (1986), se tornaram obras de referência, e foram traduzidas em vários idiomas.

José Guilherme também tinha uma verve polemista, e teve embates com Marilena Chauí $^{4}$, José Arthur Giannotti ${ }^{5}$, Ricardo Musse ${ }^{6}$, entre outros; no caso de Chauí (a quem acusou de plagiar Claude Lefort), esta controvérsia lhe valeu um estigma de "neoliberal" e "reacionário" que o acompanharia pelo resto da vida. (cf. CUNHA, 2011) Mesmo o obituário de Merquior escrito por Marcelo Coelho para a Folha de São Paulo tem um tom agressivo, acusando o recém-falecido de possuir uma "opinião conformista com relação à sociedade ocidental" (COELHO, 1991, p. 3).

Embora seja muito enfatizada a divergência ideológica de José Guilherme com a esquerda (em parte devido à própria hegemonia da mesma na intelligentsia nacional), poucos perceberam que o ideário liberal deste pensador não era idêntico ao neoliberalismo teorizado por autores como Friedrich Hayek (1899-1992) e Milton Friedman (1912-2006) e praticado por estadistas como Margaret Thatcher (1925-2013) e Ronald Reagan (1911-

\footnotetext{
${ }^{3}$ Refiro-me ao "sentimento de exclusão do Brasil da 'história universal"”, cabendo ao pensamento intelectual “procurar o tanto quanto possível imitar a 'civilização' para diminuir a distância em relação a ela” (LYNCH, 2013, p. 743).

${ }^{4}$ Ver MERQUIOR, José Guilherme. De Lefort a Marilena: que democracia? In: O Argumento Liberal. Rio de Janeiro: Nova Fronteira, 1983 e CORRÊA, Marcos Sá. Um mestre da polêmica. Revista Veja. São Paulo: Abril, edição especial n 26, edição 1821, 24 de setembro de 2003.

Link: http://veja.abril.com.br/especiais/35_anos/ent_merquior.html

${ }^{5}$ Ver MERQUIOR, José Guilherme. Retórica Ex Cathedra: Resposta a José Arthur Giannotti. Novos Estudos. São Paulo: CEBRAP, 2008.

Link: http://novosestudos.uol.com.br/v1/files/uploads/contents/53/20080623_retorica.pdf

${ }^{6}$ Ver COPETTI, Rafael Zamperetti. A Polêmica Literária no Suplemento Letras da Folha de S. Paulo (19891990). Boletim de Pesquisa NELIC v. 5, n. 6/7 - Polêmicas. Santa Catarina: Periódicos UFSC, 2003, pp. 58-69.
} 
2004). Aliás, algumas das críticas mais contundentes de Merquior em seus últimos escritos se dirigiram justamente ao "preceito econômico que, tomado equivocadamente por uma ética liberal, degrada o liberalismo a um baixo hedonismo utilitário.” (MERQUIOR, 2014, p. 174)

Sendo assim, o propósito deste trabalho é analisar a doutrina do liberalismo social tal como defendida por José Guilherme Merquior. Pretendo abordar as principais influências que Merquior mescla no seu ideário político: o "liberalismo de esquerda" de Thomas Hill Green (1836-1882), Leonard Hobhouse (1864-1929) e Keynes (1883-1946); o liberalismo humanista, preocupado com a Bildung (formação cultural), de Humboldt (1768-1835); a ênfase na individualidade de Stuart Mill (1806-1873); a síntese democrático-liberal de Raymond Aron (1905-1983) e Norberto Bobbio (1909-2004); e o liberismo (isto é, o liberalismo economicista, laissez-faire) de Hayek.

Por fim, cabe investigar, a partir das críticas de Merquior não só ao neoliberalismo, mas também à social-democracia (criticada por sua insistência no estatismo econômico), e como ele se situava no debate político no Brasil dos anos 1980, época marcada pelo processo de redemocratização e por uma aguda crise econômica, culminando na expressão "década perdida".

Dentre as referências deste trabalho constam tanto autores que vêem Merquior como neoliberal, como Roberto Campos (1917-2001), quanto os que lhe atribuem o rótulo de social-liberal, como Hélio Jaguaribe (1923). Ao longo do trabalho vou confrontar estas interpretações.

\section{A visão de mundo de Merquior}

Ao longo de sua trajetória intelectual, Merquior gradualmente mudou sua visão de mundo, embora tenha mantido sua preocupação com a crise da cultura moderna. Em sua juventude, simpatizava com o estruturalismo ${ }^{7}$ francês - principalmente com Lévi-Strauss (1908-2009) - e com a crítica cultural da Escola de Frankfurt. A principal obra desse período é o ensaio Saudades do Carnaval - Introdução à crise da cultura (1972), na qual o

\footnotetext{
${ }^{7}$ Segundo Merquior, esta escola de pensamento social parte do conceito de estrutura como "um conjunto de relações abstratas definidas de modo formal e subentende um modelo válido para vários conteúdos diferentes, sendo estes ditos isomórficos exatamente porque compartilham a mesma estrutura." (MERQUIOR, 1991b, p. 19).
} 
diagnóstico da modernidade oscila entre uma visão decadentista da cultura - parcialmente amparada na crítica de Alexis de Tocqueville (1805-1859) ao individualismo nas sociedades democráticas - e uma tímida aposta na revalorização da participação política e no potencial construtivo da crítica cultural.

A partir da segunda metade da década de 1970, entretanto, José Guilherme se afastou dessas influências: passou a considerar que tanto os estruturalistas (e pós-estruturalistas ${ }^{8}$ ) quanto o marxismo ocidental ${ }^{9}$ partiam de dois pressupostos equivocados: "sua Kulturkritik pessimista, não baseada em nenhuma análise concreta, e sua rejeição sumária da modernidade e da ciência." (ROUANET, 2014, p. 363) Anos depois, escreveu que o marxismo ocidental - embora em De Praga a Paris (1987) esta crítica também seja aplicada ao pós-estruturalismo - “foi apenas um episódio na longa história de uma velha patologia do pensamento ocidental cujo nome é, e continua a ser, irracionalismo." (MERQUIOR, 1987, p. 277)

Duas figuras que contribuíram para essa transição de Merquior para o liberalismo em política e economia e para o racionalismo em epistemologia foram, respectivamente, o diplomata e economista Roberto Campos, de quem José Guilherme foi conselheiro na embaixada de Londres, e o sociólogo Ernest Gellner (1925-1995), seu orientador no doutorado em Sociologia pela London School. Os ensaios compilados em As Idéias e as Formas (1981) marcam o momento em que José Guilherme, diante de sua constante preocupação com a crise da cultura moderna, passou a tomar partido pelo progresso e pela modernidade, adotando uma perspectiva liberal e "neo-iluminista". Para este autor, permanecia legítima a tarefa de "tornar o homem mais livre, (...) aumentar sua racionalidade, e (...) refinar sua sensibilidade artística, num mundo em que a beleza seja irmã da razão e inseparável da liberdade." (ROUANET, 2014, p. 370)

Se em sua juventude Merquior simpatizava com ideário social-democrata de San Tiago Dantas (1911-1964), a partir dos anos 70 “experimentou, como Roberto Campos, um

\footnotetext{
${ }^{8}$ O pós-estruturalismo, que abrange autores como Foucault (1926-1984) e Derrida (1930-2004), critica o paradigma estruturalista a partir de uma perspectiva formalista (que consiste na preferência pela "análise imanente" em vez de abordagens mais contextuais) e de uma apropriação niilista e decadentista do pensamento de Nietzsche (1844-1900).

${ }^{9}$ Vertente do pensamento marxista caracterizada pela epistemologia "humanística" (isto é, a adoção de uma abordagem hermenêutica e a crítica do naturalismo "cientificista"), pelo forte investimento na crítica cultural (tanto da arte erudita quanto da cultura de massa) e pelo ecletismo conceitual. (cf. Merquior, 1987: 19) Dentre seus principais representantes podem ser citados Lukács (1885-1971), Gramsci (1891-1937), Horkheimer (1895-1973), Marcuse (1898-1979) e Adorno (1903-1969).
} 
profundo desencanto com a máquina do Estado, que o levou ao campo do liberalismo." (JAGUARIBE, 2014, p. 331) José Guilherme, entretanto, se interessava pelo liberalismo para além da discussão político-econômica, encarando-o como uma visão de mundo (Weltanschauung) identificada com a crença no progresso. (cf. MERQUIOR, 2014, p. 87). Além disso, uma visão liberal "implica tanto uma forma de pensamento quanto favorece um impulso estético"; em ambos os casos "valoriza-se a autonomia frente a dogmas, estimulando-se o experimentalismo frente a tradições cristalizadas.” (ROCHA, 2014, p. 319)

Este tema permeia um dos principais ensaios de Merquior, A Natureza do Processo (1982), obra esta que trata da evolução social, política e econômica do Ocidente nos últimos três séculos, e emana uma filosofia da história progressista, inspirada em Hegel (17701831). ${ }^{10}$ Para além da defesa da democracia liberal e da economia de mercado, José Guilherme enfatiza a dimensão cultural do mundo moderno. Para este autor a cultura é, por um lado, "um complexo de valores e ideias em transformação constante" (ROCHA, 2014, p. 317); por outro, ele a concebe "no velho sentido humanístico da palavra: cultura como autocultivo, cultura como fenômeno eminentemente perfectivo" (MERQUIOR, 1982, p. 212) e também como fator fundamental para o pleno desdobramento dos potenciais da civilização moderna. Desta forma, Merquior nutria uma visão teleológica da cultura: ela é concebida como um constante esforço de auto-aperfeiçoamento dos indivíduos e sociedades.

Ao longo da década de 80, José Guilherme escreveu uma trilogia de ensaios sobre escolas ou atores que ele associava ao irracionalismo e à crítica decadentista da modernidade: Michel Foucault ou O Niilismo da Cátedra (1985); O Marxismo Ocidental (1986); e De Praga a Paris (1986). Seu último livro, O Liberalismo: Antigo e Moderno (1989), contudo, possui um tom mais construtivo e propositivo: por trás de uma história das ideias liberais, revela-se uma "inesperada autobiografia intelectual de José Guilherme Merquior. No fundo, seu testamento.” (ROCHA, 2014, p. 322)

Nesta obra há um movimento simultaneamente centrífugo e centrípeto: se por um lado o autor descreve a "impressionante variedade dos liberalismos" (MERQUIOR, 2014, p. 262), por outro sua capacidade de síntese lhe permite evitar a dispersão, e dizer o essencial de cada autor analisado. Por ser uma exposição objetiva, as convicções do próprio Merquior

\footnotetext{
${ }^{10}$ Esta influência hegeliana no pensamento de Merquior, no entanto, é mais bem explicada em $O$ Marxismo Ocidental. Hegel teria ajudado a legitimar uma visão histórica do homem e aceitou, de forma madura, o espírito da sociedade moderna, "com sua crescente divisão do trabalho, a expansão das liberdades individuais e uma nova compreensão da capacidade do homem para moldar a história." (MERQUIOR, 1987, p. 53)
} 
não são apresentadas de forma explícita, mas podem ser subentendidas na avaliação mais ou menos favorável que tece sobre cada uma as correntes e personalidades do pensamento liberal. (cf. JAGUARIBE, 2014, p. 333)

\section{A posição de Merquior diante das vertentes liberais}

Uma importante precaução metodológica adotada por José Guilherme em $O$ Liberalismo: Antigo e Moderno foi dividir o liberalismo em escolas nacionais; com isso evitou um problema recorrente nas obras sobre o tema, que é sobredimensionar o pensamento anglo-saxão. (cf. Ibidem, p. 333)

A primeira das escolas é justamente a inglesa, a qual tende a conceber a liberdade de forma negativa ${ }^{11}$, i.e., como ausência de obstáculos externos. Seu precursor foi Thomas Hobbes (1588-1679), que "iguala liberdade com tudo o que a lei permite pelo simples fato de que não proíbe.” (MERQUIOR, 2014, p. 53). O principal liberal britânico foi John Stuart Mill, que exaltou a liberdade do indivíduo de "procurar o seu próprio bem à sua própria maneira" (MILL, 1859 apud MERQUIOR, 2014, p. 130), mesmo que o cultivo de sua individualidade se oponha à maioria da opinião pública.

A tradição francesa, ao contrário, tem um viés mais republicano, e enfatiza a liberdade positiva, isto é, que se dá por meio da participação política. Jean-Jacques Rousseau (17121778), embora não seja ele próprio um liberal, contribuiu para o redirecionamento do conceito de liberdade da esfera civil para a esfera cívica. (cf. MERQUIOR, 2014, p. 54) O maior dos liberais franceses foi Alexis de Tocqueville, pensador bastante preocupado com a patologia social do "individualismo" (isto é, a falta de virtude pública) nas sociedades democráticas. Diante dos riscos da crescente centralização administrativa (isto é, a concepção de um poder único, central e de legislação uniforme) acarretar em um

\footnotetext{
${ }^{11}$ Sobre a dicotomia das liberdades estabelecida por Isaiah Berlin (1909-1997), eis uma breve explicação: a liberdade positiva é um anseio de autonomia, uma aspiração de autogoverno; ou seja, é a conquista do domínio de si mesmo, da auto-realização. Já a liberdade negativa significa a estar livre de coerção pela vontade arbitrária dos outros; é a ausência de restrições ou limitações externas ao indivíduo, na medida em que cada pessoa deve ser independente, livre de interferências e capaz de agir segundo as próprias escolhas. Ver BERLIN, Isaiah. Dois conceitos de liberdade. In: Estudos sobre a Humanidade: Uma Antologia de Ensaios. São Paulo: Companhia das Letras, 2002.
} 
“despotismo democrático", Tocqueville cultivava esperanças no autogoverno local e de associação voluntária.

A terceira dessas escolas é a alemã, marcada por uma temática mais cultural do que econômica ou política: Kant (1724-1804) trata da autotelia (realização pessoal) e Humboldt, da Bildung, isto é, o cultivo da personalidade através da formação cultural, visando ao desdobramento do potencial humano. (cf. Ibidem, p. 57) A propósito, uma das passagens mais marcantes de $O$ Liberalismo: Antigo e Moderno é justamente sobre um dos maiores representantes do liberalismo alemão:

\footnotetext{
Humboldt exprimiu um tema liberal profundamente significativo: a preocupação humanista de formação da personalidade e aperfeiçoamento pessoal. Educar para a liberdade, e libertar para educar - esta era idéia da Bildung, a contribuição goethiana de Humboldt à filosofia moral. (Ibidem, p. 56)
}

Cabe notar que a adesão de Merquior à ideia humboldtiana de "aperfeiçoamento pessoal" já havia aparecido em Algumas Reflexões sobre os Liberalismos Contemporâneos (1986), ao ressaltar que a conexão entre liberalismo e humanismo é "permeada pelo tema da excelência, da autoformação". (Idem, 1991, pp. 15-16)

Depois de discutir as contribuições dos principais expoentes do liberalismo clássico, José Guilherme trata de uma reviravolta ideológica ocorrida no século XIX: o surgimento dos liberalismos conservadores. Os excessos da Revolução Francesa levaram o pensamento liberal a adquirir uma desconfiança diante da política de massas: era "preciso proteger a sociedade das oscilações entre um populismo irresponsável e um dogmatismo repressivo." (JAGUARIBE, 2014, p. 337)

Ao contrário dos conservadores stricto sensu, cuja perspectiva se funda no tradicionalismo, numa visão organicista da sociedade e no ceticismo político (cf. MERQUIOR, 2014, p. 141), os liberais conservadores acreditavam no progresso e partiam de uma visão individualista; porém, ambos os grupos se aproximavam em sua desconfiança da democracia. Autores como Herbert Spencer (1820-1903) Lorde Acton (1834-1902) e mesmo o argentino Alberdi (1810-1884) procuraram retardar a democratização da política liberal, e pregavam a "ampliação cautelosa da inclusão do povo nos direitos políticos". (Ibidem, p. 183) O próprio Tocqueville, em sua obra tardia (em especial as Lembranças de 1848), demonstrou certa aversão à política de massas. 
No quinto capítulo de O Liberalismo: Antigo e Moderno, "Dos novos liberalismos aos neoliberalismos", José Guilherme discorre uma linhagem de pensadores pouco conhecida hoje em dia, mas que teve enorme impacto nas políticas públicas do século XX: o liberalismo social, cujos principais representantes são Thomas Hill e Leonard Hobhouse. A questão social ganhou relevância em decorrência dos efeitos por vezes perversos da Revolução Industrial, como o grande contingente de pessoas empobrecidas e com condições de vida precárias nas grandes cidades. Merquior constata que essa inflexão social do liberalismo no fim do século XIX parte de uma "discussão de caráter eminentemente moral, e não de qualquer espécie de economicismo" (PAIM, 1992, p. 46), marcada pela crítica à ética individualista dos primeiros liberais e ao seu corolário político, o "Estado-mínimo":

\begin{abstract}
O liberalismo clássico fizera recair o peso da justificação sobre a interferência estatal. Normalmente, o Estado devia deixar que a cidadania livremente tratasse de seus negócios. Sua interferência só era legítima em benefício da segurança individual, como uma garantia da livre determinação pela sociedade da maior felicidade para o maior número. Green não era tão minimalista. A função do Estado, ensinou, devia consistir na "remoção de obstáculos" ao autodesenvolvimento humano. Isso era também uma idéia alemã, decorrente de Humboldt. O Estado nunca se podia pôr no lugar do esforço humano para a Bildung, ou cultura pessoal, mas podia e devia "promover condições favoráveis à vida moral”. (MERQUIOR, 2014, p. 188)
\end{abstract}

Green concebia a liberdade como o direito que se tem de produzir o melhor de si mesmo, "conjugando os valores básicos dos direitos e liberdades individuais com uma nova ênfase na igualdade de oportunidades e no éthos de comunidade." (Ibidem, p. 189) Hobhouse, por sua vez, revelava uma preocupação com a justiça social e com os excessos do laissez-faire preconizado pelo liberalismo clássico, e desejava demonstrar que a sociedade progride por força da cooperação humana, e não (apenas) pelo auto-interesse dos atores sociais.

Embora mantenha caráter individualista, para o liberalismo social a liberdade é algo valioso apenas na medida em que seja meio para um fim: o bem comum. Ao contrário do liberalismo conservador, cuja característica principal é a desconfiança em relação à democracia, os social-liberais valorizam a participação política e o pluralismo. Para esta vertente, não se trata de uma discussão sobre mais ou menos Estado, mas sim de mais ou menos liberdade - ou seja, algo como uma "democratização da Bildung":

Os novos liberais queriam implementar o potencial para o desenvolvimento do indivíduo que fora caro a Mill em seguimento a Humboldt, e ao fazê-lo pensaram 
no direito e no Estado como instituições habilitadoras. Esta preocupação com a liberdade positiva levou-os a ultrapassar o Estado minimalista. (Ibidem, p. 200)

José Guilherme, portanto, endossa a noção do liberalismo social de que a liberdade é algo a ser desfrutado por todos os membros da sociedade, contanto que as linhas de ação livremente escolhidas não envolvam dano a outrem. Nesse sentido, cabe ao Estado aprimorar a igualdade de oportunidades, para que não apenas uma minoria da população possa usufruir materialmente da liberdade pessoal.

Um dos autores que deram continuidade a esse "liberalismo de esquerda" foi o economista John Maynard Keynes, cujas ideias foram fundamentais para a renovação do capitalismo após a Grande Depressão. Embora mantenha a crença de Stuart Mill de que só uma sociedade com valores liberais permite um extenso "campo para o exercício das escolhas pessoais" (KEYNES, 1996, p. 346), Keynes também se preocupa com a crescente desigualdade social decorrente da crise econômica; nesse sentido, defende que uma maior atuação do Estado na economia seria "o único meio exeqüível de evitar a destruição total das instituições econômicas atuais e (...) condição de um bem-sucedido exercício da iniciativa individual" (Ibidem, p. 347). Em suma, ressalta que "o problema político da humanidade consiste em combinar três coisas: eficiência econômica, justiça social e liberdade individual.” (KEYNES, 1931 apud MERQUIOR, 2014, p. 210)

A partir da década de 1940, entretanto, começou uma gradual reação a essa vertente socializante do liberalismo e seu resultado prático, o welfare state. Ludwig von Mises (1881-1973) e Friedrich Hayek, principais economistas da Escola Austríaca, contribuíram para o ressurgimento do liberismo, isto é, da ênfase na liberdade econômica. Hayek alega que a intervenção estatal na economia é negativa "porque faz com que a rede de informações do sistema de preços emita sinais enganadores, além de reduzir o escopo da experimentação econômica." (MERQUIOR, 2014, p. 228)

Nos anos 70, este ideário - que ganhou legitimidade acadêmica depois que Hayek (em 1974) e Milton Friedman (em 76) ganharam o Prêmio Nobel de Economia - se configuraria politicamente no neoliberalismo" : a partir da "convicção de que o progresso deriva automaticamente de uma soma não-planejada de iniciativas individuais", propõe-se "um

\footnotetext{
12 José Guilherme considera o rótulo "neoliberalismo" caricatural, pois os liberalismos contemporâneos abrangem muito mais do que um mero retorno passadista ao liberalismo econômico do século XIX. A revalorização do liberismo não necessariamente implica em uma exclusão da ênfase igualitária que o pensamento liberal adquiriu no século passado (cf. MERQUIOR, 1991a, p. 7).
} 
desmantelamento do social-liberalismo, um retorno em regra ao Estado mínimo". (Idem, 1981c, p. 22) Os neoliberais acreditam na tese da indivisibilidade da liberdade: "a menos que se obtenha ou se mantenha a liberdade econômica, as outras liberdades - civil e política - se desvanecem.” (Idem, 2014, p. 229)

O ideário neoliberal, contudo, não se limita a "retroceder a um puro favorecimento do laissez-faire ou ao modelo de Estado vigia noturno" (Ibidem, p. 229); para Hayek, as duas únicas funções legítimas do governo consistem “em prover uma estrutura para o mercado, e prover serviços que o mercado não pode fornecer" (Ibidem, p. 228) - e a segunda delas é relativamente flexível. Em O Caminho da Servidão (1944), por exemplo, este autor afirma que "não há incompatibilidade entre o Estado oferecer maior segurança auxiliando na organização do sistema de previdência social e a preservação da liberdade individual" (HAYEK, 2010, p. 128).

Um dos principais expoentes do neoliberalismo no Brasil, Roberto Campos alega, no prefácio que escreveu para $O$ Liberalismo: Antigo e Moderno, que em seus últimos anos de vida Merquior estava se aproximando do liberismo:

\footnotetext{
Em nossas últimas conversas senti que José Guilherme se tornava cada vez mais "liberista". Neste credo, comungávamos. O "liberista" é aquele que acredita que, se não houver liberdade econômica, as outras liberdades - a civil e a política desaparecem. Na América Latina, a concentração de poder econômico é um exercício liberticidade. Nosso diagnóstico sobre a moléstia brasileira era convergente. Ao Brasil de hoje não falta liberdade. Falta liberismo. (CAMPOS, 2014, p. 29)
}

Esta interpretação, no entanto, não me parece convincente, afinal a avaliação que Merquior faz dos liberistas é bastante crítica. Sobre Hayek, por exemplo, o autor aponta uma "cega confiança (...) na ciência da evolução como tradição", na medida em que ele afirma, mais do que prova, "a sabedoria oculta de instituições há muito existentes" (MERQUIOR, 2014, p. 232). Este adesão quase mística à “ordem espontânea” poderia justificar inclusive instituições intervencionistas, como o controle de preços e a taxação progressiva. Além disso, "a liberdade, para Hayek, é, no fundo, um instrumento de progresso; o mérito supremo do indivíduo 'hayekiano' é contribuir (inconscientemente) para a evolução social" (Ibidem, p. 233). Tal visão neo-evolucionista, aos olhos de José Guilherme, afasta o 
economista austríaco de uma abordagem mais sofisticada, como os social-liberais e sua síntese do individualismo de Mill e do humanismo de Humboldt. ${ }^{13}$

Em O Argumento Liberal, Merquior considera o neoliberalismo uma "utopia liberalconservadora", deficiente em matéria de visão histórica e consciência social e incapaz de atender "aos impulsos democratizantes das sociedades industriais de modelo liberal”, muito menos às "exigências sociais dos países, como Brasil, onde a 'síntese democrático-liberal' permanece incompleta." (Idem, 1981c, p. 22)

A propósito, esta "síntese democrático-liberal" é justamente o que José Guilherme encontra no sociólogo Raymond Aron e no jurista Norberto Bobbio. Ambos permitem a Merquior contrapor ao "hedonismo utilitário" dos neoliberais um liberalismo com apelo mais democrático, apto a responder à altura os desafios políticos colocados pelas transformações sociais das últimas décadas.

José Guilherme afirma que Aron valorizava a espontaneidade da economia, compreendendo o capitalismo moderno como "única garantia da eficácia produtiva e da sociedade liberal" (Idem, 1981a, p. 14); contudo, ao contrário dos neoliberais, aceitava o Estado-previdência e não via a democracia representativa como entrave para a liberalização econômica. Aron postulava "um amálgama de direitos civis e políticos tradicionais com modernos direitos sociais, que ele representa como direitos-créditos (droits-créances)." (Idem, 2014, p. 238) Numa perspectiva surpreendentemente atenta ao problema periférico, José Guilherme afirma que, para um "liberal do Terceiro Mundo", o pensamento de Aron é muito mais frutífero do que o de Hayek:

...o reconhecimento da síntese liberal-democrática tornou Aron, em vez de liberal-conservadores como Hayek ou os pensadores anglo-saxônicos da Nova Direita, um autor muito querido aos liberais modernos da América do Sul, especialmente na minha própria geração (...) - a de um Celso Lafer em São Paulo ou um Marcílio Moreira no Rio. (Idem, 1987, pp. 273-274)

Bobbio, outro autor que busca compatibilizar liberalismo e democracia, rejeita a “estadofobia” de liberistas como Hayek e Robert Nozick (1938-2002), pois acredita que

\footnotetext{
${ }^{13}$ Merquior também opera esta crítica ao evolucionismo de Hayek em Reflexões sobre os Liberalismos Contemporâneos: "Hayek estaria escrevendo, cada vez mais, como um Spencer redivivo. Ou seja, um homem que abraça, sempre mais, uma perspectiva evolucionista, a ponto mesmo de diluir, dissolver a perspectiva ética, o plano do juízo ético, da avaliação ética, numa visão evolucionista (...) insustentável. Menciono isso como última pílula daquilo que é, hoje, problemático no desenvolvimento da obra de Hayek: o fato de que ele está soando, em tom sempre mais intenso, como um Spencer sofisticado, numa clara volta às posições básicas do evolucionismo de final do século passado." (MERQUIOR, 1991a, 11)
} 
“qualquer retraimento do direito público é sinal de decadência política, real (como no início da Idade Média) ou intelectual (como na teoria social de Spencer)." (Idem, 2014, p. 258) Merquior enaltece a preocupação deste jurista italiano em compreender quais são as estruturas e controles institucionais de poder adequados para uma democracia genuína, a qual para Bobbio "é necessariamente uma democracia liberal". (BOBBIO, 1980 apud MERQUIOR, 2014, p. 257; grifos no original). Bobbio também afirma que a "atenção ao condicionamento material da(s) liberdade(s), a preocupação com a instauração efetiva de uma democracia social, em absoluto não elimina o problema político-constitucional da liberdade" (MERQUIOR, 1981b, p. 214).

A partir dos posicionamentos de José Guilherme diante das diversas vertentes do liberalismo (clássico, conservador, social, liberista e democrático), é possível perceber, em primeiro lugar, as reservas do autor diante dos liberal-conservadores e dos neoliberais, na medida em que os pensadores ligados a essas correntes demonstram temores diante da democracia e, no caso dos liberistas, ainda rechaçam a própria ideia de justiça social (Hayek, por exemplo, a considera nada mais que uma "miragem") $)^{14}$.

Em segundo lugar, é possível notar sua inclinação pelo liberalismo social. Para Merquior, "a liberdade moderna é compósita e dinâmica, feita de direitos, obrigações e oportunidades em constante mudança", portanto "a democratização do liberalismo permanece em pauta." (Ibidem, p. 230) Em outras palavras, José Guilherme acreditava que "a liberdade política será sempre precária sem o aperfeiçoamento da igualdade." (ROUANET, 2014, p. 364) Sendo assim, o pensamento de autores como Hobhouse e Keynes são "as chaves de entendimento das ideias de Merquior para pensar o Brasil do final dos anos oitenta e início dos anos noventa.” (ALMEIDA, 2008, p. 5)

\section{O liberalismo social: "terceira via" ou neoliberalismo enrustido?}

Esclarecida a posição de José Guilherme Merquior diante das principais correntes do pensamento liberal, cabe agora sondar as considerações deste autor sobre a socialdemocracia, na medida em que, dentre as ideologias políticas contemporâneas, ela é considerada o único contraponto viável ao neoliberalismo. Desta forma será possível definir

\footnotetext{
${ }^{14}$ Ver o volume 2 de HAYEK, Friedrich August von. Direito, legislação e liberdade: uma nova formulação dos princípios liberais de justiça e economia política. Trad. Maria Luiza X. de A. Borges. São Paulo: Visão, 1985.
} 
se Merquior seria um neoliberal, como dizem Roberto Campos ou mesmo seus detratores, ou se sua doutrina do liberalismo social possui algum débito com o ideário socialdemocrata.

Em A Natureza do Processo, José Guilherme faz críticas duras ao marxismo (o qual considerava superado como proposta teórica) e ao "neossocialismo" (termo que cunhou para designar os intelectuais de inclinação libertária e anti-produtivista); porém, seu juízo sobre a social-democracia é relativamente positivo. O grande mérito dela teria sido a restauração da diferença entre socialismo e comunismo: antes dessa síntese (que teria sido realizada por Karl $\operatorname{Marx}^{15}$ [1818-1883]), os socialistas eram os reformistas e democratas que se preocupavam com a base social da liberdade e combatiam as formas de exploração econômica que marcaram o "capitalismo selvagem" dos primórdios do industrialismo (cf. MERQUIOR, 1982, p. 165).

No pós-guerra, a social-democracia se encaminhou para um reformismo social ditado pela aspiração ao welfare state e a um capitalismo "keynesiano" - aceitando, portanto, a economia de mercado e a democracia representativa. Os partidos social-democratas, portanto, não só aderiram à competição democrática no plano político, mas também passaram a partilhar o próprio poder econômico, tornando-se assim aptos a "reduzir bastante as desigualdades e carências sociais" (Ibidem, pp. 166-167).

Merquior compartilhava a tese de Raymond Aron de que nem os governos liberalconservadores de Thatcher e Reagan seriam capazes de reverter a compatibilidade de longo prazo entre capitalismo e social-democracia: as "exortações neoliberais" não foram capaz de explicar, por exemplo, "por que o maior período de elevado e contínuo crescimento econômico do mundo moderno" - i.e., de 1945 a 1973 - "pôde conviver muito bem com o planismo e o incremento da previdência social" (Ibidem, p. 169-170).

O louvor à social-democracia, no entanto, tem limites: ela não é tão consistente quanto o liberalismo social para equacionar os problemas sociais, políticos e econômicos contemporâneos. José Guilherme admite que a insistência de certos governos no estatismo econômico (por exemplo, os trabalhistas britânicos na década de 70) explica sua derrota política e ideológica frente ao moderno liberalismo. (cf. ALMEIDA, 2008, p. 2) O trecho a

\footnotetext{
15 "O que Marx fez foi, ao mesmo tempo, economicizar o comunismo e politizar o socialismo. Marx ensinou o comunismo a falar a linguagem da economia e injetou o princípio comunista da política revolucionária na tradição produtivista do socialismo" (MERQUIOR, 1987, p.71; grifos no original)
} 
seguir faz uma crítica implícita à mentalidade nacional-desenvolvimentista que ainda predominava no Brasil, nos anos 1980:

(...) o Estado latino-americano típico, e o brasileiro em particular, está longe de ser filantrópico. Nosso Estado "social" na verdade reproduz privilégios, ao mesmo tempo em que cerceia a dinâmica de crescimento por alimentar a inflação crônica, interminavelmente reabastecida pelas atitudes e demandas cartoriais de grupos sociais particularistas. Por isso, emagrecer o Estado - o que não significa, ao contrário do que pretende o liberalismo conservador, aboli-lo, ou reduzi-lo a mero gendarme - é um imperativo atualmente embutido na própria exigência das reformas de estrutura sugeridas pelo diagnóstico das nossas taras sociais. Pois somente o emagrecimento do Estado permitirá a redefinição de suas funções, em favor do social e do planejamento sem estatismo. (MERQUIOR, 1989 apud ALMEIDA, 2008, p. 6)

José Guilherme parece defender uma espécie de "terceira via" (isto é, uma socialdemocracia "modernizadora", mais transigente com o livre mercado ${ }^{16}$ ) no artigo Brazil's New Republic: The Social-Liberal Path (1987) quando alega, em concordância com Hélio Jaguaribe, que o crescimento econômico é condição necessária, mas não suficiente do desenvolvimento social: "O capitalismo não é um anátema, mas o mercado não é visto como um meio adequado de suprir as necessidades sociais" (MERQUIOR, 1987, p. 271). Merquior, contudo, toma a liberdade individual e não a igualdade social como ponto de partida de sua concepção política:

O conceito social-liberal (...) reside na capacidade de conceber a liberdade moderna como um equilíbrio complexo entre liberdade e justiça, autonomia individual e direito coletivo. A igualdade não é buscada como um objetivo final, mas como uma ferramenta flexível usada para ampliar a liberdade pessoal - daí a preferência por igualar oportunidades e não condições. A liberdade tende a prosperar com oportunidades justas [fair chances] (Ibidem, p. 273).

Referindo-se à conjuntura político-partidária brasileira do fim dos anos 1980, Merquior rechaça tanto o PDS, que representaria a "nova direita brasileira, semelhante ao Thatcherismo ou à Reagonomics" (Ibidem, p. 272), quanto o radicalismo vagamente

\footnotetext{
${ }^{16}$ Desenvolvido pelo sociólogo Anthony Giddens (1938), o conceito de "terceira via" parte da constatação de que as antigas divisões de esquerda e direita, baseadas em classes sociais, se tornaram redundantes. Sendo assim, os governos reformistas não poderiam mais se basear em programas estatistas diante de uma sociedade cada vez mais globalizada e de uma economia mais financeirizada. (cf. MELLBYE, 2003) Giddens apoia o compromisso da social-democracia com a igualdade de oportunidades, a justiça social e a coesão social, mas critica o seu estatismo por negligenciar a aspiração individual e a inovação sufocante. Ao mesmo tempo, abraça a ênfase neoliberal no dinamismo e a eficiência dos mercados, mas rejeita soluções universais de mercado por não reconhecerem a necessidade de um governo ativo e por ameaçarem o tecido social. (LEGGETT, 2007) O corolário da "terceira via" consiste, em vez do welfare state, em um modelo de "Estado de investimento social". Dentre os líderes políticos que se consideraram adeptos da "terceira via" podem ser citados Tony Blair (1953), Bill Clinton (1947), Fernando Henrique Cardoso (1931), Gerhard Schröder (1944) e Lionel Jospin (1936).
} 
anticapitalista do PT e o "socialismo moreno" do PDT. Sua aposta é no reformismo moderado, de centro-esquerda, do PMDB, que em sua heterogeneidade lembra os Democratas da época de Roosevelt (1892-1945), com sua “estranha, mas efetiva mistura de componentes conservadores e progressistas" (Ibidem, p. 272). A fórmula política da Aliança Democrática entre PMDB e PFL se assemelha à social-democracia, com resquícios do nacional-desenvolvimentismo; mas, há um elemento liberal herdado de Afonso Arinos (1905-1990), criador da expressão “Nova República”. Para Merquior, o caminho socialliberal desse novo regime "equivale a uma via media entre o estatismo antiquado da esquerda e a estatofobia excessiva da nova direita" (Ibidem, p. 275).

Enquanto José Guilherme apostava nessa combinação de elementos socialdemocráticos e liberais e da Aliança Democrática, é interessante notar que Roberto Campos - que se filiava ao pensamento neoliberal e era politicamente mais conservador que Merquior - tinha fortes reservas quanto ao governo do PMDB e PFL. Crítico de Tancredo Neves, considerava-o "um acomodatício e não um reformador; em sua vida política jamais ousara afastar-se do paradigma de adulação do nacionalismo e dos monopólios estatais" (CAMPOS, 1999, p. 455). Além disso, lamentava a própria formação do PFL (uma dissidência do PDS, partido de sustentação ao regime militar), pois acreditava que uma vitória do liberal-conservador Paulo Maluf nas eleições presidenciais de 1985 teria impedido que fossem cometidos “os quatro pecados mortais que explicam a 'década perdida' (198594) - o Plano Cruzado (1986); a moratória unilateral (1987); a expansão do nacionalismo informático e dos monopólios estatais; e a Constituição de 1988” (Ibidem, p. 456).

Em sua última conferência, O Brasil no limiar do século 21 (1990), Merquior defende um "neocapitalismo produtivo". Em oposição ao capitalismo elitista, especulativo e sustentado por um Estado patrimonial que predomina até nossos dias no Brasil, propõe-se uma "refuncionalização" do Estado: em vez de produtor, deve ser promotor do bem-estar coletivo. É preciso abandonar o estatismo em prol de um Estado estrategista, pois "há uma diferença muito grande entre os sonhos de certos neoliberais de quase eliminação do Estado" e a necessidade do mesmo "no que diz respeito a certas definições estratégicas quanto ao futuro de nossa economia e de nossa sociedade" (MERQUIOR, 2001, p. 11). Também cabe ao Estado o papel de "protetor dessas imensas camadas da população brasileira que carecem de teto, que não comem apropriadamente, que não dispõem de escola e de acesso à Justiça" (Ibidem, p. 11). 
José Guilherme não limitou sua contribuição ao debate teórico; também manifestou sua militância liberal na imprensa, publicando artigos em jornais como $O$ Globo e Jornal do Brasil. Durante as eleições de 1989, escreveu vários textos nos quais combateu a noção de que haveria uma polaridade entre as propostas dos candidatos Luís Inácio Lula da Silva (mais voltadas para a redução das desigualdades sociais) e Fernando Collor de Mello (direcionadas para a modernização do Estado). Para José Guilherme, o próprio êxito na luta contra a desigualdade passa pela reforma do Estado:

O eixo da argumentação de Merquior passa pela defesa de que as demandas distributivistas de caráter imediatista implicam um alto grau de intervenção na economia, seja na estipulação de salários, seja nas tentativas de criar ou manter subsídios ou, ainda, de controlar preços, levando a mais inflação e não a menos desigualdade. A solução, portanto, seria o combate à inflação sem deixar de perseguir a redistribuição de renda através do enfrentamento da dívida interna e do déficit público. A médio prazo, o Estado empreenderia igualmente uma reforma fiscal e outra patrimonial, assegurando maior liquidez ao Tesouro e maior eficiência à ação governamental. No centro de tal proposta encontra-se a defesa das privatizações uma vez que pela reforma patrimonial, o Estado privatizaria as estatais onerosas, gerando com isso maior receita, além de diminuir sua custosa carga burocrática (ALMEIDA, 2008, p. 6).

Collor venceu aquela eleição adotando uma retórica liberal em economia ${ }^{17}$, e convidou Merquior para escrever seu discurso de posse. O texto consistia "numa profissão de fé na economia de mercado (...) e fazia advertências contra o 'redistributivismo inconseqüente em prejuízo do esforço produtivo"” (PILAGALLO, 2002, p. 184). Há uma defesa da liberalização da economia (por meio de privatizações e abertura ao comércio internacional), visando a modernizar o país e aproximá-lo do modelo adotado nos países industrializados. (cf. Ibidem, p. 184) Eis uma das passagens que evocam o ideário do liberalismo social:

Ao Estado corresponde planejar sem dirigismo o desenvolvimento e assegurar a justiça, no sentido amplo e substantivo do termo. O Estado deve ser apto, permanentemente apto, a garantir o acesso das pessoas de baixa renda a determinados bens vitais. (...) Entendo assim o Estado não como produtor, mas como promotor do bem-estar coletivo. Daí a convicção de que a economia de mercado é forma comprovadamente superior de geração de riqueza, de desenvolvimento intensivo e sustentado (MELLO, 1990, p. 15).

\footnotetext{
${ }^{17}$ Muito embora o próprio Collor não tivesse muita clareza quanto a suas próprias convicções, como demonstra uma curiosa conversa entre o ex-presidente e Merquior, em meados de 1990:

"- Embaixador, preciso de uma base ideológica. Falam que eu sou de direita, e para mim a direita é o Delfim Netto e o Roberto Campos. O senhor me vê como político de direita?

- Não. O vejo como um socialista liberal.

— Mas não há uma contradição entre o socialismo e o liberalismo?

— Não. O Norberto Bobbio usa e defende essa classificação - disse o diplomata, apoiando-se nas teorias do cientista político italiano.” (CONTI, 1999, p. 336)
} 
Neste discurso aparecem temas que serão desenvolvidos nos textos escritos por José Guilherme como base programática do Partido Social Liberal Brasileiro que Fernando Collor pretendia fundar; propõe-se, acima de tudo, "a atualização do liberalismo clássico diante das novas demandas promovidas pela crise que os Estados capitalistas de modernização tardia atravessavam." (ALMEIDA, 2008, p. 9). No Brasil do fim da década de 80, a transição democrática, consolidada pela Constituição de 1988 e pelas eleições diretas de 1989, coexistia com a hiperinflação, a recessão econômica e a crise da dívida externa (cf. PILAGALLO, 2002, pp. 176-177). Diante desse cenário político-econômico, Merquior propunha "a manutenção dos pressupostos fundamentais do liberalismo conciliando-os com profundas reformas do aparelho do Estado e com a garantia de direitos sociais." (ALMEIDA, 2008, p.10)

Em suma, é possível dizer que José Guilherme sustentava um liberalismo que equilibra a maximização da liberdade com uma ampla exigência de equidade social; portanto, ao contrário do estereótipo que foi criado em torno dele, estava longe de endossar o neoliberalismo. (cf. JAGUARIBE, 2014, p. 348) Logo, não é possível tomar sua perspectiva sociopolítica como um neoliberalismo disfarçado (o que poderia ser alegado por uma perspectiva mais à esquerda ou nacional-desenvolvimentista) tampouco como uma "terceira via" (como poderia sugerir sua postura transigente com a social-democracia), mas sim como uma "retomada criadora do social-liberalismo." (MERQUIOR, 1981c, p. 22)

\section{Conclusão}

A análise que empreendi do pensamento político de José Guilherme Merquior me permitiu constatar que sua defesa do liberalismo social, no plano teórico, é uma tentativa de conciliar liberdade e igualdade, valorizando mais a participação política do que o liberalismo clássico, o conservador e o liberista. A proposta social-liberal também é um esforço de aproximar o liberalismo do ideal da Bildung, isto é, de uma ética humanista, uma visão mais nobre da condição humana . Também foi possível notar suas críticas à social-democracia, por sua insistência no estatismo econômico, e a duas vertentes em particular do pensamento liberal: a conservadora (por sua desconfiança da democracia) e a liberista ou neoliberal (por enfatizar excessivamente a liberdade econômica). Para o autor, o escopo da atuação do Estado não deve ser minimalista, na medida em que lhe cabe moderar a desigualdade social: 
Há uma percepção crescente de que no Brasil o Estado é um paradoxo vivo. Em poucas palavras, há tanto excesso quanto carência dele. Excesso de Estado, é claro, na esfera econômica, onde o que antes era um planejamento central saudável acabou por engendrar burocracias mastodônticas e um setor estatal vasto, gordo e desajeitado, gritando por racionalização e privatização. Carência, é evidente, na provisão ou promoção de serviços sociais a massas carentes, especialmente onde apenas o Estado realizaria tarefas não lucrativas (Idem, 1987, p. 275).

Ao longo da década de 80, José Guilherme também argumentou, tal como Norberto Bobbio, em prol da democracia liberal, e se opôs tanto ao conservadorismo quanto ao socialismo: "o liberalismo é, das nossas três grandes ideologias políticas, a única a levar profundamente a sério o ideal democrático no sentido rigoroso da palavra, de governo do povo." (Idem, 1981b, pp. 23-24)

Antes de encerrar este artigo, julgo pertinente fazer um breve balanço crítico da contribuição de José Guillherme Merquior para o pensamento político brasileiro. Em primeiro lugar, não se pode ignorar que por vezes Merquior portou-se como um doutrinário, com uma fé inabalável em uma filosofia da história iluminista com toques hegelianos. Nesse sentido, Martim Vasques da Cunha critica-o por evocar uma "divinização da História", isto é, por acreditar que o sentido da História era imanente, e que o resultado inevitável do processo histórico seria o progresso e equilíbrio das instituições. José Guilherme também é acusado de nutrir uma visão ingênua do Estado:

\footnotetext{
Sua visão equilibrada do Estado é uma doce idealização. Merquior parece se esquecer da sua raiz expansionista, em que, para preservar a natureza secreta do poder, se desdobra em inúmeros tentáculos de maneira tão sutil que o ataque à alma individual se torna imperceptível (CUNHA, 2015, p. 556).
}

Em segundo lugar, a colaboração de Merquior com Fernando Collor ainda é foco de controvérsia. Alguns vêem ingenuidade em sua aproximação com o ex-presidente, enquanto outros vêem ambições políticas: na opinião de Paulo Mercadante (1923-2013), "Merquior tinha sonhos políticos (...). Certa vez, ele me disse que havia se preparado intelectual e culturalmente para dar o pulo na política, tal como o fizera, décadas antes, San Tiago Dantas." (SINGER, 2001, p. 7)

Em terceiro lugar, poder-se-ia alegar que o ideal social-liberal de José Guilherme de fato foi aplicado nos últimos vinte anos, pelos governos de Fernando Henrique Cardoso e Lula, mas a sua proposta de um Estado promotor teria sido incapaz de conter a aceleração do processo que Tocqueville denominava "centralização administrativa": 


\begin{abstract}
Mesmo com o aparente rompimento de suas ideias em relação ao Plano Collor uma verdadeira intervenção estatal digna da URSS - o prestígio de Merquior perdurou mesmo após sua morte, com a eleição de Fernando Henrique Cardoso para a presidência. FHC defenderia o papel de Estado que Merquior via como "equilibrado" - e hoje o PT se apropria da mesma retórica da social-democracia obscurantista para legitimar o aparelhamento ideológico das instituições a serviço do mito da "revolução permanente". (por sinal, um termo que se origina do liberalismo clássico francês). Sabemos no que isso deu: em um falso liberalismo no qual os direitos individuais que a lei deveria assegurar são distorcidos, em função dos direitos coletivos, prejudicando o indivíduo (CUNHA, 2015, p. 557; Idem, 2011).
\end{abstract}

Crítica semelhante é feita por José Oswaldo de Meira Penna (1917): o socialliberalismo de Merquior seria uma ideologia "de conteúdo indefinível e inspiração keynesiana, que parece se querer apossar do governo brasileiro para salvar o Estado patrimonialista falido de uma merecida perda de legitimidade” (PENNA, 1997, p. 512).

Por fim, uma crítica mais pontual diz respeito à ausência de liberais brasileiros em $O$ Liberalismo: Antigo e Moderno. Embora autores incomuns em enciclopédias do pensamento liberal apareçam na obra, dentre eles os argentinos Sarmiento (1811-1888) e Alberdi e o espanhol Ortega y Gasset (1883-1955), não há nenhuma menção a pensadores importantes como Tavares Bastos (1839-1875), Joaquim Nabuco (1849-1910) e Rui Barbosa (18491923). ${ }^{18}$ Infelizmente, o cosmopolitismo de Merquior, que supera "o preconceito de restringir a discussão das grandes ideias públicas ao universo euro-norte-americano" (JAGUARIBE, 2014, p. 338), não se aplica a seu próprio país - embora, no âmbito da crítica literária, ele tenha escrito uma história da literatura brasileira em De Anchieta a Euclides (1977).

A despeito dessas ressalvas, cabe reconhecer que a contribuição deste autor ao pensamento liberal é notável, pois se constrói a partir de uma síntese de vários autores desta tradição intelectual. João Cezar de Castro Rocha afirma que a caracterização que Merquior faz de Aron poderia servir ao próprio autor de O Liberalismo: Antigo e Moderno: "Seu liberalismo lúcido, muitas vezes cáustico, sempre demasiado cônscio das contradições da modernidade" (MERQUIOR apud ROCHA, 2014, p. 322).

\footnotetext{
${ }^{18}$ Hélio Jaguatibe também lamenta que outros autores latino-americanos, como os mexicanos Benito Juárez (1806-1872), Porfirio Diaz (1830-1915) e o chileno Diego Portales (1793-1837), também não tenham sido incluídos na obra. (cf. JAGUARIBE, 2014, p. 338)
} 


\section{Referências}

ALMEIDA, Monica Piccolo. José Guilherme Merquior e Fernando Collor de Mello: O Moderno Liberalismo Social. Anais do Segundo Congreso Internacional: La Escuela Austríaca en el Siglo XXI. Rosário, 2008.

BERLIN, Isaiah. Dois conceitos de liberdade. In: Estudos sobre a Humanidade: Uma Antologia de Ensaios. São Paulo: Companhia das Letras, 2002.

CAMPOS, Roberto. Merquior, o liberista. In: MERQUIOR, José Guilherme. O Liberalismo: Antigo e Moderno. São Paulo: É Realizações, 2014, p. 19-31.

Na Virada do Milênio. Rio de Janeiro: Topbooks, 1999.

COELHO, Marcelo. Merquior uniu espírito polêmico a conformismo social. Folha de São Paulo. Caderno Letras. São Paulo, 12 de janeiro de 1991, p. 3.

CONTI, Mário Sérgio. Notícias do Planalto. São Paulo: Companhia das Letras, 1999.

CUNHA, Martim Vasques da. A Poeira da Glória. Rio de Janeiro: Record, 2015.

O cadafalso da inteligência brasileira. Dicta \& Contradicta (site). 24 de agosto de 2011. Link: http://www.dicta.com.br/o-cadafalso-da-inteligencia-brasileira/ Acesso em 26 de novembro de 2014.

HAYEK, Friedrich. O Caminho da Servidão. Trad. Anna Maria Capovilla, José Ítalo Stelle e Liane de Morais Ribeiro. São Paulo: Instituto Ludwig von Mises Brasil, 2010.

JAGUARIBE, Hélio. Merquior e o liberalismo. In: MERQUIOR, José Guilherme. $O$ Liberalismo: Antigo e Moderno. São Paulo: É Realizações, 2014, p. 331-349.

KEYNES, John Maynard. A Teoria Geral do Emprego, do Juro e da Moeda. Trad. Mário R. da Cruz. São Paulo: Nova Cultural, 1996.

LEGGETT, Will. Third Way (Giddens). In: RITZER, George (ed.) Blackwell Encyclopedia of Sociology. 2007. Disponível em: http://www.blackwellreference.com/public/tocnode?id=g9781405124331_chunk_g9781405 12433126_ss1-56 Acesso em 21 de junho de 2017.

LYNCH, Cristan Edward Cyril. Por que pensamento e não teoria? : A imaginação políticosocial brasileira e o fantasma da condição periférica (1880-1970). Dados. Rio de Janeiro, Vol. 56, No 4, 2013, p. 727-767. 
MARGUTTI, Paulo. História da filosofia do Brasil (1500-hoje): $1^{a}$ parte: o período colonial (1500-1822). São Paulo: Edições Loyola, 2013. Resenha de: RAZZO, Francisco. Nabuco: revista brasileira de humanidades. $\mathrm{N}^{\circ}$ 1, Agosto de 2014. São Luís: Edições Nabuco, 2014, p. 169-176.

MELlBYE, Anne. A brief history of the third way. The Guardian. Disponível em: https://www.theguardian.com/politics/2003/feb/10/labour.uk1 Acesso em 19 de junho de 2017.

MELLO, Fernando Collor de. O Projeto de Reconstrução Nacional. Discurso de Posse. 15 de março de 1990. Disponível em: http://www.biblioteca.presidencia.gov.br/expresidentes/fernando-collor/discurso-de-posse Acesso em 26 de novembro de 2014.

MERQUIOR, José Guilherme. Algumas Reflexões sobre os Liberalismos Contemporâneos. Rio de Janeiro: Instituto Liberal, 1991a.

. A Natureza do Processo. Rio de Janeiro: Nova Fronteira, 1982.

Aron e as ideologias. In: Raymond Aron na UnB: conferências e comentários de um simpósio internacional realizado de 22 a 26 de setembro de 1980. (Itinerários). Brasília: Editora Universidade de Brasília, 1981a, p. 13-23.

. As Idéias e as Formas. Rio de Janeiro: Nova Fronteira, $1981 \mathrm{~b}$.

. O Brasil no limiar do século 21. Folha de São Paulo. Caderno Mais!. São Paulo, 15 de julho de 2001, pp. 8-11.

O Argumento Liberal. Revista Tempo Brasileiro, n 65/66. Rio de Janeiro: Tempo Brasileiro, 1981c, p. 17-24.

Brazil's New Republic: The Social-Liberal Path. Bulletin of Latin American Research, Vol. 6, No. 2, 1987, pp. 269-277.

. De Praga a Paris. Rio de Janeiro: Nova Fronteira, 1991b.

. O Liberalismo: Antigo e Moderno. São Paulo: É Realizações, 2014.

. O Marxismo Ocidental. Rio de Janeiro: Nova Fronteira, 1987.

PAIM, Antonio. Merquior e a Questão do Liberalismo Social. Revista Tempo Brasileiro, $\mathrm{n}^{\circ}$ 109. Rio de Janeiro: Tempo Brasileiro, 1992, pp. 45-58. 
PENNA, José Oswaldo de Meira. O Espírito das Revoluções. Rio de Janeiro: Faculdade da Cidade Ed., 1997.

PILAGALLO, Oscar. O Brasil em sobressalto: 80 anos de história contados pela Folha. São Paulo: Publifolha, 2002.

ROCHA, João Cezar de Castro. A visão do mundo de José Guilherme Merquior: esta reedição. In: MERQUIOR, José Guilherme. O Liberalismo: Antigo e Moderno. São Paulo: É Realizações, 2014, p. 311-324.

ROUANET, Sérgio Paulo. Merquior: obra política, filosófica e literária. In: MERQUIOR, José Guilherme. O Liberalismo: Antigo e Moderno. São Paulo: É Realizações, 2014, p. 360370.

SINGER, André. O enigma Merquior. Folha de São Paulo. Caderno Mais! São Paulo, 15 de julho de 2001, pp. 4-7.

Recebido em 22-11-2016;

Revisado em 17-04-2017;

Publicação em 04-05-2018. 
